\title{
Wildfire Rehabilitation and Restoration: Triage in the Pursuit of Resilience
}

\section{By Charlie D. Clements, Gary McCuin, Ryan S. Shane, Kent McAdoo, and Dan N. Harmon}

$7 \sqrt{ }$ orkshop V, "Wildfire Rehabilitation and Restoration" of the Wildfires and Invasive Plants in American Deserts Conference and Workshops held in Reno, Nevada, in December 2008, provided the opportunity for many resource managers, researchers, students, the general public, and other interested parties to engage in discussions concerning natural resource challenges such as invasive weeds and wildfires. This workshop consisted of four talented and experienced speakers and was moderated by the talented and dedicated Dr Tamzen Stringham, Associate Professor, Rangeland and Riparian Scientist, Department of Animal Biotechnology, University of Nevada, Reno. The four speakers were 1) Mike Zielinski, a soil scientist with the Bureau of Land Management, US Department of the Interior (USDI), where he has worked closely with the restoration/ rehabilitation of habitats damaged by wildfires for more than 20 years in the Winnemucca, Nevada District. 2) Mike Pellant, Great Basin Restoration Initiative Coordinator, Bureau of Land Management, USDI, Boise, ID. Mr Pellant uses his experience to provide technical assistance in restoration/rehabilitation projects throughout the Great Basin. 3) Dr Bruce Roundy, Professor of Range Science, Department of Plant and Wildlife Sciences at Brigham Young University. Dr Roundy has spent more than 30 years as a researcher on such topics as restoration/rehabilitation of Intermountain West rangelands. 4) David Repass, National Program Lead for the Bureau of Land Management, USDI, Wildfire Emergency Stabilization and Rehabilitation Program, where he has led the charge on these efforts during some of the most active wildfire seasons in recent history.

The speakers presented an excellent summary of pertinent scientific and practical knowledge, which the audience drew upon when participating in the panel discussion and in completing workshop questionnaires. Mike Zielinski presented case studies of habitat restoration within the Winnemucca District, in which the successful seeding of perennial grasses was essential in reducing cheatgrass (Bromus tectorum L.) densities in order to decrease wildfire frequencies and allow the reestablishment of shrubs. Mike Zielinski pointed out that this is sometimes a very slow process, much slower in the Wyoming big sagebrush (Artemisia tridentata subsp. wyomingensis) communities than the mountain big sagebrush (A. tridentata [Beetle \& Young] subsp. vaseyana [Rydb.] Beetle) communities. Mike Pellant emphasized how important it is to make good decisions on when and where seeding efforts should take place. For example, post-fire restoration practices will not likely be needed in mountain big sagebrush communities where native perennial grasses are well represented and cheatgrass densities are minimal. Conversely, post-fire restoration/rehabilitation efforts are often needed at lower elevation, more xeric Wyoming big sagebrush sites where the perennial grass is absent or nearly absent and cheatgrass densities are much greater. Mountain big sagebrush communities often have an excellent chance of returning to communities dominated by native herbaceous species and are less likely to attain cheatgrass dominance than Wyoming big sagebrush communities. He also pointed out the importance of greenstripping to proactively reduce the spread of wildfires and protect critical habitats. Mike Pellant also spoke passionately about post-seeding management and monitoring, stressing the importance of being on the ground to record the effects of restoration/rehabilitation practices in order to better understand why particular projects succeed or fail.

Bruce Roundy reiterated some of the points made by Zielinski and Pellant, such as a greater need for rehabilitation efforts in the Wyoming big sagebrush and salt desert shrubs communities over that of the mountain big sagebrush communities. He emphasized the importance of seeding the first fall following the wildfire and how important it is to get these rehabilitation efforts completed during the short window of opportunity before cheatgrass can increase and dominate the site. Once cheatgrass dominates the site, restoration costs increase due to the need for aggressive and 
effective practices of control. Dr Roundy also pointed out that what you may need to seed on a site in order to initiate restoration may not be what you ultimately want at a particular site. However, always use species that are adapted to the site and the conditions on the ground.

Given that these talks took place in Reno, Nevada, it is fitting to say that seeding efforts on rangelands is a crapshoot; the odds are that these catastrophic wildfires are followed by below-average precipitation, which is the "nail in the coffin" for many seeding projects. Lower than average precipitation may not allow successful establishment of seeded species, which will then provide a noncompetitive environment to invaders. Dr Roundy stated that average precipitation never really occurs and is not a dependable statistic. Historic climate cycles indicate that 1 or 2 years of favorable precipitation are typically followed by many dry years.

David Repass expressed how important it is to be prepared to address the restoration/rehabilitation needs following catastrophic wildfire events, which ultimately need to protect human life and property. Many natural resource policy and logistical issues arise from fire-destabilized sites, including erosion (i.e., dust over the highway, mudslides), National Environmental Policy Act (NEPA) documentation, wildland seed purchasing, and contracting challenges. Mr Repass emphasized the need to aggressively prioritize projects and direct those funds to those habitats with the highest deemed value or risk (i.e., unstable slopes adjacent to structures, sage grouse strutting ground, mule deer wintering habitat) and to monitor these efforts to better learn from successes and failures.

\section{Panel Discussion Bullets}

The panel discussion predominately covered the areas of policy, science, and management. Is the 21-day time frame for the Emergency Stabilization Plan (ES) feasible and can this policy be more flexible? Repass commented that it would probably not be a bad idea to take another look at that time frame, but that in some instances, this time frame is critical as dust control or mudslide dangers may be an immediate threat to life and property. Also, there was a suggestion that when the Bureau of Land Management purchases seed, it would be a good idea to include other agencies. Mr Repass acknowledged that there are ongoing discussions to partner with other government agencies and private entities to pool resource funds and purchases. Post-wildfire funds are allocated for 3 years, and seeding implementation is the first year priority, while second and third years are dedicated to monitoring and other long term objectives. In some cases, this first year implementation of seeding is not achieved in a timely manner such that seed is broadcasted on top of snow or even drilled as late as the following March; should this policy be practiced? Mike Zielinski responded that in his experience, the seeding implementation should occur no later than early February, though preferably in October or November.
The panel was asked if consideration of seed mix composition should be a derivative of what species are present in the seed bank, whether there were enough native species pre-fire to have a native seed bank representation, or whether the seed bank is dominated by cheatgrass or other undesirable species. The panel replied that many times, the preexisting vegetation and seed bank data are not available outside research plots. It was acknowledged that the species most adapted to the site conditions and with the best chance of success may indeed be an introduced species such as crested wheatgrass (Agropyron cristatum L.) or 'Immigrant' forage kochia (Kochia prostrata L.). Dr Roundy pointed out that it in many cases, the species you want to use for rehabilitation may not be the species that can successfully be established when seeded in these harsh environments and under the current conditions. For example, using forage kochia on former blackbrush (Acacia rigidula Benth.) sites when blackbrush cannot be successfully reestablished.

A member of the audience voiced their concern about post-fire management of fire disturbed habitats, stating that it is important to do proper post-fire management and not just walk away. As Mike Pellant pointed out in his presentation, post-treatment grazing management to promote the survival and vigor of the seeded species is critical. What about when these seeding efforts fail? Does the postfire management promote buildup of cheatgrass fuels and increased fire frequency? Decisions must be made by actively monitoring conditions on the ground. Monitoring of these treatments may only be funded for 3 years, but the problem on the ground can be catastrophic if not managed each year, for the long-term. Often these restoration/ rehabilitation efforts fail, yet these habitats are critical to the overall health of the ecosystem and the wildlife species that depend on these habitats. You simply cannot walk away and forget about these habitats.

\section{Audience Questionnaire Responses}

The nearly 300 questionnaires received consisted of two general questions: 1) What is the most critical issue, challenge, or goal that must be addressed for wildfire rehabilitation and restoration to affect resilience? and 2) What is the best strategy for success? Responses were stratified into the following five areas.

\section{Science Recommendations}

The majority of comments related to science addressed the desire to continue research on the development of plant materials that can be successfully established in the field and can compete with and suppress cheatgrass. All of these efforts could help provide the foundation for a decision support tool for on-the-ground resource managers on when, what, where, and how to seed, as well as prioritizing all rehabilitation projects and needs.

- Managers are interested in addressing the question "what level of cheatgrass density dictates unsuccessful native species seeding and necessitates less socially preferred but 
more competitive nonnative species such as crested wheatgrass?"

- The use of seeding greenstrips to protect critical habitats may be desirable, but researchers need to develop innovative approaches using the successes of these nonnative greenstrips and find methods of seeding native species into these sites using processes like assisted succession.

- The practice of "assisted migration" (to assist plant species to establish and develop populations outside their current range) and incorporation of existing climate changes and cycles should be better understood and used to explain success or failure: "we may have to muster the courage to engage in assisted migration to determine desired outcomes in managing the products of succession."

- Increased emphasis needs to be placed on the autecology of native species or how individual species respond to changing environmental conditions. The participant commented that "the lack of autecology information inflicts flexibility in seeding dates; our success will improve when we plant each species at a time and in a manner that mimics their natural dispersal, incorporation, and germination process." Would there be an increase in success if restoration/rehabilitation efforts focused on not just one or two seeding methods at one time, but used a number of seeding times and techniques?

- Research is needed on the ability and potential of native species to oust competing cheatgrass. Additionally, there is need for the development of plant materials that are genetically equipped to thrive on drier and hotter sites.

- There should be more emphasis on plant material centers to grow a variety of native species such as Thurber's needlegrass (Achnatherum thurberianum Piper) for restoration efforts and provide the seed source to researchers. Researchers could then conduct plant material testing on a variety of sites with different potentials, soil types, and cheatgrass densities.

\section{Management and Policy Essentials and Changes}

Reading the nearly 300 questionnaires, it is clear that there is a strong belief from the conference attendees that there is a disconnect between administration policies and biological/environmental reality:

- Wildfires are now occurring May through September and as one respondent stated, with "June/July/August fires, ES has to be done in 21 days (too short of a time period to do a good job), which is occurring through August and September, and then too late to contract for that Fiscal Year."

- Funds are available for 3 years, in which the first year usually goes into seeding followed by fencing and then monitoring the third year. It is very clear in these responses that restoration/rehabilitation sites need to be monitored beyond 3 years. Additional monitoring results would improve our understanding of successful and unsuccessful restoration/rehabilitation practices and could drive appropriate and adaptive management beyond the initial fire restoration/rehabilitation period.

- Policies and funding do not realistically relate to existing environmental conditions and obstruct effective restoration/rehabilitation efforts. These policies must be more flexible, and the funding needs to carry over a longer period of time, to accommodate conditions that favor resource planning goals. "The fire season is not going to change to accommodate the fiscal year and therefore the fiscal/procurement system needs to adapt and change."

- Recognize seeding as one of the most valuable, effective, and proven methods used to restore functional and desired ecosystems.

- Seed what works (i.e., species and methods), which includes seeding the first fall following the wildfire to take advantage of this short but very important window before cheatgrass has the opportunity to take the site over (Fig. 1).

- Seed high priority sites that have a greater potential for success (i.e., don't seed sites dominated by cheatgrass and burned so fast that you can still see cheatgrass seed on the surface of the soil, unless you are willing to establish an active and effective weed control program to improve seeding success). Protection of adjacent unburned habitats using seeding efforts should be a high priority as well.

- Unburned islands containing mother plants of important native seed provide native seed for either assisted or unassisted restoration/rehabilitation efforts and research. Establish policies to ensure that these islands are considered valuable and are not burned out by suppression and mop-up crews. Additionally, utilize presuppression treatments such as greenstrips to provide a barrier between intact communities and communities with undesirable conditions.

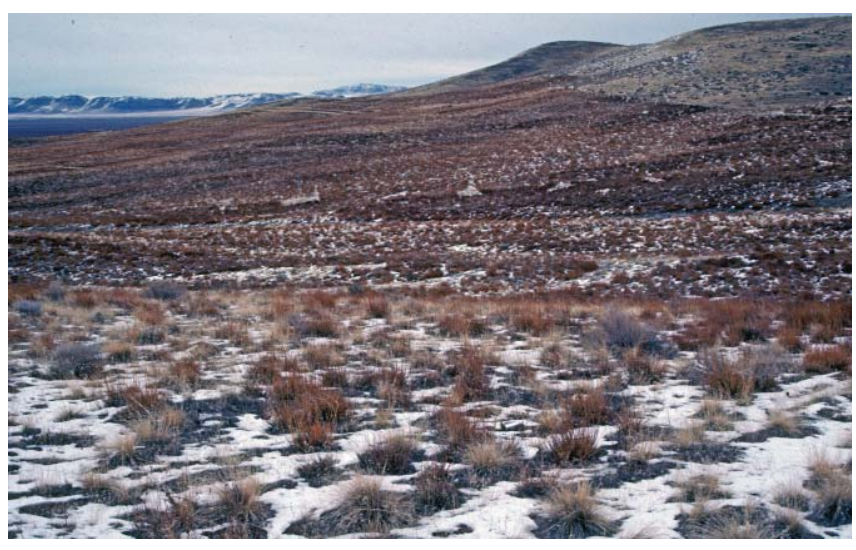

Figure 1. A successful seeding in northeastern Nevada where a mix of introduced and native species was used and seeded using both a rangeland drill (species that require being placed in the ground) and the method of dropping the seed on the ground followed by a culti-packer (seed that does well on the surface or just below the surface of the soil). Notice the unseeded habitat in the far right corner, dominated by cheatgrass. 
- Being proactive appears to be a solution in the eyes of many resource managers because they view land management agencies as reactive and always trying to catch up versus placing boots on the ground. Having better prefire site descriptions (i.e., soil mapping, ecological site descriptions, state and transition models) would allow more appropriate restoration/rehabilitation planning. Data sharing between agencies and organizations could expedite data collection and distribution if efforts were planned and coordinated. The development and use of various technologies to collect, store, and distribute resource data, including meteorological predictions, cycles, and patterns, would prove useful for those weighing and determining the implementation of restoration/ rehabilitation methods, practices, and associated risks.

- The primary goal should be to disrupt the current destructive wildfire cycles that promote invasive species: "we must get beyond the bias of seeding natives versus nonnatives and be willing to take intermediate steps to break the frequent fire cycles." As Mike Zielinski, Bruce Roundy, and Mike Pellant stated, "you may have to seed species that you do not prefer because those are the species that have the best chance of success and can establish in the current conditions on the ground. Would you rather have cheatgrass, or worse invasive species such as medusahead (Taeniatherum caput-medusae [L.] Nevski), or crested wheatgrass and forage kochia?" In addition to species composition management, fuels management is also necessary no matter what species contribute to fuel loads.

- There is also a lot of concern about the lack of cooperation/communication among agencies: "everybody is doing something, but nobody knows what the other agencies are doing." Increased cooperation among the many entities (i.e., local, state, federal, and private) would improve the knowledge base, build partnerships, and improve restoration/rehabilitation efforts and success.

- Managers would also like to know how decisions are made, as one individual responded, "do we need research that tells us what actually drives decisions (i.e., seed, money, personnel, visible from some individual's home, etc.)?"

- Post-fire management also needs to "step it up a notch." We have already established that monitoring of these sites well past the 3 years is necessary. What about livestock grazing following seeding efforts? Failed seedings result in the buildup of cheatgrass fuels, the need for fuels management. These and many other on-the-ground realities occur frequently and are going unmanaged. These issues all play a role in the occurrence of catastrophic wildfires and the successes and failures of expensive restoration/rehabilitation efforts.

\section{Funding Ideas and Priorities}

As you may expect, funding is very important, and everyone wants to be funded; however, wanting it and getting it are two very different things.
- The largest area of input came in the form of a desire to form partnerships to increase available funds, and to place these funds in carryover accounts, or "establish restoration/rehabilitation accounts that can carry over from year to year to take advantage of extra funds left over from mild fire seasons." These funds should be available for fuels management and enable agencies to become proactive. Through multiagency partnerships, agencies and communities could be more economically and operationally efficient in terms of seed purchases, sharing of equipment personnel, and monitoring.

- An innovative approach would be a multiagency/-entity effort at increasing the exposure of the destructive nature of wildfires to life, property, plant community function, and health (clean water). Increased public awareness of the financial costs to the public, and the adverse resource impacts of catastrophic wildfires, should improve public support for proactive resource management and facilitate raising funds to address these critical issues. Conference participants suggested contracting a public relations firm to increase public awareness and increase public appetite to fund wildland restoration/rehabilitation projects both pre- and post-fire. All funds generated from this effort should be placed in a carryover account to allow for multiyear spending, and allowed as matching funds for federal and state projects and grants. This effort would help provide necessary funds for agencies and communities to become more effective and comprehensive in pre- and post-fire resource management.

\section{Outreach Audiences and Strategies}

There was very positive feedback to continue and broaden conferences/workshops like this one at perhaps SRM 2010.

- Provide research updates, communicate success stories derived from this workshop or others, and publish these accomplishments/successes in a coffee table type magazine that the general public would want and enjoy reading (e.g., Rangelands).

- Use reporting that could more easily reach out to congressional leaders and their staff, and convey the resource challenges associated with wildfire and vegetation conversion in a concise and understandable manner.

- Whether successful or failed, results should be compiled in annual reports and published during the spring (online as well) so that resource managers get annual updates on known successes and failures, so that efforts can have a better chance of being more effective.

\section{Education or Training Objectives by Target}

\section{Audience}

Again, there was very good feedback on continuing conference/workshops like this one.

- Make conferences and updates mandatory for those individuals making the decisions, such as state directors.

- Managers would like to have access to a synthesis and analysis of these workshops that could provide 
instruction on adaptable plant materials for specific sites, seeding methodologies, effective weed control practices, equipment, and other information from past literature to better prepare themselves to make more informed and effective decisions.

- Develop desert-specific or regionally specific guidelines on effective or preferred restoration/rehabilitation practices and plant materials. In addition, provide materials on post-rehabilitation practices and objectives that aid in restoration of desired fire regimes.

\section{Food for Thought}

There is no doubt that the introduction and subsequent invasion of exotic and invasive weeds such as cheatgrass have resulted in destructive and catastrophic wildfires that have made wholesale changes to western rangelands (Fig. 2). The best known method at suppressing cheatgrass is through the establishment of long-lived perennial grasses (Fig. 3). Pioneer range scientist Charles Fleming stated

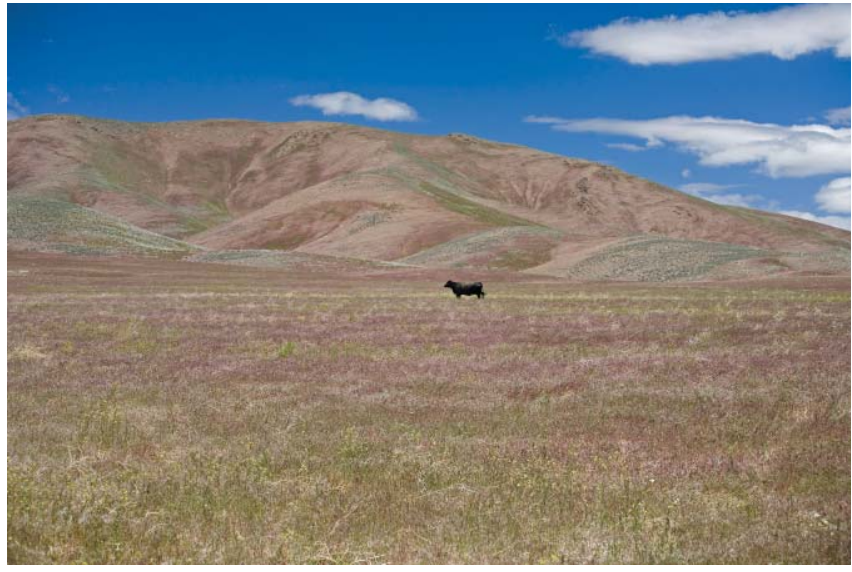

Figure 2. Formerly big sagebrush/bunchgrass community converted to cheatgrass dominance following cheatgrass-fueled wildfire. This cycle must be slowed down and reversed, or the loss of whole plant communities and the wildlife that depend on them are soon to be memories. Photo by Bob Blank, Soil Scientist, USDA-ARS, Reno, Nevada.

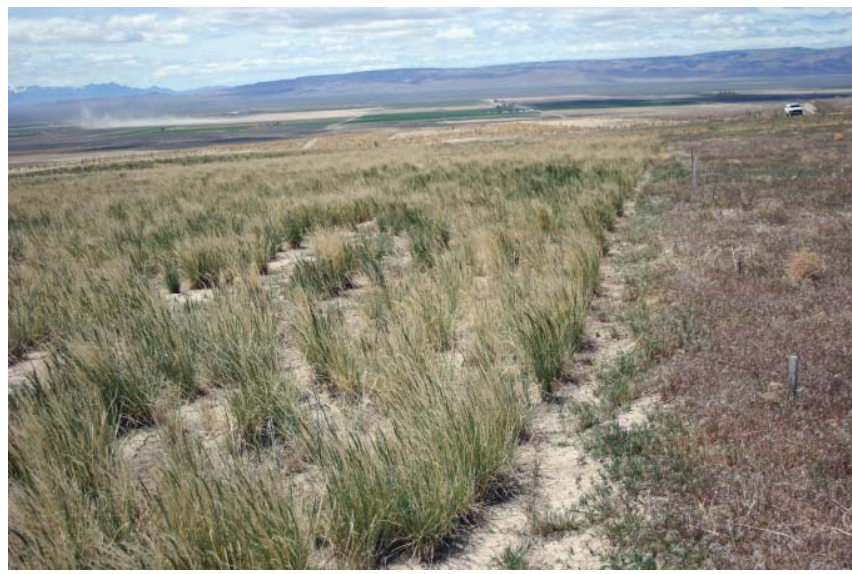

Figure 3. The establishment of long-lived perennial grasses is a must if cheatgrass densities and fuel loads are to be decreased along with the catastrophic wildfires that follow.
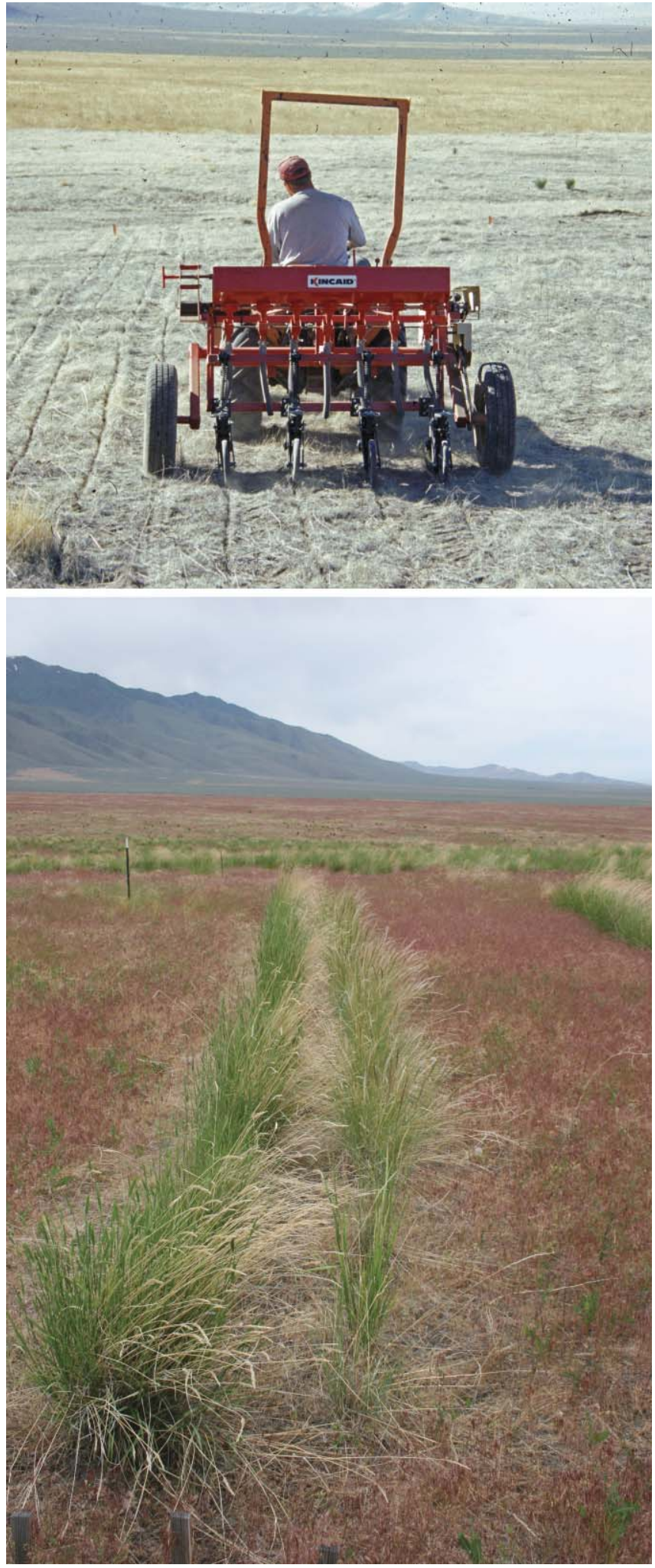

Figure 4. (top) Kincaid experimental drill in which a variety of tests such as seed species (native or introduced), germplasm (local versus commercial), seed densities, seed mixes, and seeding methodologies (no-till, furrows, weed control) can be conducted and reported efficiently and economically. (bottom) Notice that after 16 species were tested (4 forbs, 4 shrubs, and 8 grasses), 2 species were successful at establishing at this site, crested wheatgrass and Sherman big bluegrass. 
more than half a century ago, "has anyone the practical method by which annuals can be replaced and perennials reestablished in a density which could permit saying that the range had been brought back to its pioneer carrying capacity... and if the answers are largely negative, will we then not have to live with the annuals and learn to make the most profitable use of them?" ${ }^{1,2}$

Plant material development and testing is not new, but further development and perhaps more innovative approaches are going to be critical if restoration/ rehabilitation efforts are to be more successful than unsuccessful. "Stopping the wildfire cycle, soil erosion and invasion of cheatgrass is a choice. Similarly, cheatgrass invasion, repeated burning, and loss of topsoil is also a choice," said Jerry Chatterton, retired Plant Physiologist, Research Leader, for the Forage and Range Research Laboratory, USDA-Agricultural Research Service (USDA-ARS), Logan, Utah. ${ }^{3}$ If the theory is that native seed or even native seed from the site is more adapted to the specific site, then where is the equipment and methodology to test this theory on the ground? Conversely, you can test a variety of both native and introduced species by seeding rates, mixes, and methods (Fig. 4). Raymond Evans, a pioneer cheatgrass researcher, reported more than 4 decades ago that as little as four cheatgrass plants per square foot were detrimental to crested wheatgrass seedling establishment. ${ }^{4}$ In an ongoing research project, the USDA-ARS, Exotic and Invasive Weeds Research Unit (EIWR) has recorded cheatgrass seed bank densities at over 100 sites in Nevada, ranging from 0 to over 1,200 seeds per square foot, averaging 252 seeds per square foot. These levels are devastating to the recruitment of native perennial species. Remember, the established perennial grass is not affected, but the competition at the seedling stage is the problem. Cheatgrass outcompetes the perennial grasses for limited resources and therefore decreases the ability of perennial grasses to recruit new plants back into the community. This becomes even more apparent when you measure cheatgrass densities following wildfires. The EIWR also recorded a sevenfold increase in cheatgrass densities the second year following a wildfire event (Wyoming big sagebrush community) compared to the first year. These facts give profound evidence of the critical decision to implement sound and effective restoration/rehabilitation practices during the very short windows of opportunity. The plant species that are used in restoration/rehabilitation efforts must have the inherent ability to germinate, sprout, and establish in these various habitats in the face of such aggressive competitors as cheatgrass.

Mike Pellant and Bruce Roundy brought up the importance of past research and past researchers, sometimes referred to as the "old timers," etc., such as Steve Monsen, who was Mike Pellant's mentor and gained much of his experience under Perry Plummer, a pioneer in restoration and rehabilitation efforts, or James A. Young, whom Bruce Roundy worked under early in his career and is well known as an encyclopedia of Great Basin rangelands. Many discoveries were made by these early researchers that often go unmentioned or even unnoticed, but their decades of experiences are treasures that could provide solutions to current challenges and should not be ignored. "If we continue over the next 20 years as we have over the past 20 years, we will not recognize the Great Basin as we have known it," said James A. Young.

\section{References}

1. Fleming, C. E., M. A. Shipley, and M. R. Miller. 1942. Bronco grass (Bromus tectorum) on Nevada ranges. Reno, NV, USA: University of Nevada Agricultural Experiment Station Bulletin No. 159. 21 p.

2. Young, J. A., and C. D. Clements. 2007. Cheatgrass and grazing rangelands. Rangelands 29(6):15-20.

3. Miller, E., and R. Narayanan [eds.]. 2008. Great Basin wildfire forum: the search for solutions. Reno, NV, USA: Nevada Agricultural Experiment Station, University of Nevada, Reno. $41 \mathrm{p}$.

4. Evans, R. A. 1961. Effect of different densities of downy brome (Bromus tectorum) on growth and survival of crested wheatgrass (Agropyron desertorum) in the greenhouse. Weeds 15:50-55.

Authors are Rangeland Scientist, charlie@scs.unr.edu (Clements), and Agricultural Research Technician (Harmon), USDA Agricultural Research Service, Reno, NV 89512, USA; Agricultural Extension Educator, University of Nevada Cooperative Extension, Eureka, NV 89316, USA (McCuin); and Resource Management Officer (Shane), Nevada Division of Forestry, and Rangeland Resources Area Extension Specialist (McAdoo), University of Nevada Cooperative Extension, Elko, NV 89801, USA. 